\title{
MaGNOLIA GUERRERENSIS (MAGNOLIACEAE), UNA ESPECIE NUEVA DEL BOSQUE MESÓFILO DE MONTAÑA Del estado de Guerrero, MÉXICO
}

\author{
Jaime Jiménez-RamírezZ ${ }^{1,4}$, Karla Vega-Flores², Ramiro CruZ-Durán ${ }^{1}$ Y \\ J. ANTONIO VÁZQUEZ-GarCíA ${ }^{3}$
}

\begin{abstract}
'Departamento de Biología Comparada, Facultad de Ciencias, Universidad Nacional Autónoma de México, Circuito Exterior s/n, Ciudad Universitaria, México 04510, D.F., México.

${ }^{2}$ Herbario y Jardín Botánico, Benemérita Universidad Autónoma de Puebla, Edificio 76, Ciudad Universitaria, Blvd. Valsequillo y Av. San Claudio s/n, Col. San Manuel, Puebla 72590, Puebla, México.

${ }^{3}$ Herbario IBUG, Departamento de Botánica y Zoología, Instituto de Botánica, Universidad de Guadalajara, km 15 carretera Guadalajara-Nogales, Las Agujas, Zapopan 45110, Jalisco, México.

${ }^{4}$ Autor para la correspondencia. Correo-e: jjr@hp.fciencias.unam.mx
\end{abstract}

\begin{abstract}
Resumen: Se propone e ilustra a Magnolia guerrerensis (Magnoliaceae) como una entidad nueva del bosque mesófilo de montaña en el estado de Guerrero, México. Este taxón es afín a M. schiedeana Schltdl., pero difiere de ésta por presentar estípulas más pequeñas, flores pediceladas y gineceo con menos carpelos. También se incluye una clave para distinguir ambas especies. Palabras clave: bosque mesófilo de montaña, Guerrero, Magnolia, Magnoliaceae, México.
\end{abstract}

\begin{abstract}
Magnolia guerrerensis from the cloud forest in the state of Guerrero, Mexico, is illustrated and proposed as a new species. This taxon is similar to M. schiedeana Schltdl., but differs from it because of its smaller stipules, pedicellated flowers and gynoecium with less carpels. A key to distinguish both species is included.
\end{abstract}

Key words: cloud forest, Guerrero, Magnolia, Magnoliaceae, Mexico

$\mathbf{E}_{\mathrm{d}}^{\mathrm{n}}$ n el estudio de la familia Magnoliaceae para el estado de Guerrero se han encontrado cuatro especies del género Magnolia: M. krusei J.Jiménez Ram. et R.Cruz en los bosques mesófilos cálidos situados a 1,500-1,850 m s.n.m., en la vertiente central del Pacífico del estado, $M$. mexicana DC. [antes Talauma mexicana, género cambiado de acuerdo con la clasificación de Figlar y Nooteboom (2004)] en bosque mesófilo a 1,500 m s.n.m. o menos, $M$. vazquezii sp. nov. (enviada a publicación) en los bosques mesófilos del oriente de Guerrero, a 2,150-2,342 m s.n.m., y la ahora propuesta $M$. guerrerensis en los bosques mesófilos del centro de la entidad (municipios de Leonardo Bravo, Heliodoro Castillo y Quechultenango) a (1950-) 2,220-2,400 m s.n.m. Tradicionalmente, los ejemplares de
M. vazquezii sp. nov. y M. guerrerensis sp. nov. han sido determinados como $M$. schiedeana Schltdl. dado que tienen un indudable parecido morfológico, pero cada una de estas tres especies posee características propias que las distinguen claramente de las otras. En esta ocasión se abordarán solamente las de M. guerrerensis y M. schiedeana Schltdl.

La distribución de las tres especies es totalmente alopátrida. Magnolia schiedeana Schltdl. solamente se encuentra en la porción central de la vertiente del Golfo de México; en cambio, $M$. guerrerensis y $M$. vazquezii se distribuyen únicamente en la porción guerrerense de la Sierra Madre del Sur, de manera que la separación geográfica es clara e indudable. Sin embargo, parece contradictorio que dos especies de Magnolia que habitan los bosques mesófilos de 
la misma cadena montañosa en el estado de Guerre ro, a una altitud similar, no tengan la misma distribución, pero si se examina la accidentada fi si ografía de la Sierra Madre del Sur es obvio que el bosque mesófilo de montaña más templado ocupa las porciones más elevadas y húmedas, lo que provoca que se formen manchones discontinuos de este tipo de vegetación (si bien es cierto que puede existir a menores altitudes un bosque mesófilo más cálido donde puede hallarse a $M$. krusei J.Jiménez Ram. et R.Cruz o a M. mexicana DC.). M agnolia guerrerensis se encuentra en la porción central de la Sierra Madre del Sur de Guerrero; en cambio, $M$. vazquezii es propia de la parte más oniental de dicha serranía. Entre ambas áreas de distri bución existen porciones más bajas y carentes de bosque mesófilo de montaña que parecen explicar la discontinuidad, como la porción donde pasa la autopista que va de Chilpancingo a Acapulco. Esta explicación coincide con las propuestas de Vázquez-García (1994) y Vázquez-García et al. (2002), quienes afi rman que las especies pertenecientes a la sección Theorhodon Spach [ahora incluidas en la sección Magnolia sensu Figlar y Nooteboom (2004)], tienen un marcado patrón de especiación alopátrida, provocada por aislamiento ge ográ fico o ecológico. El área de distri bución de las especies de la sección Theorhodon Spach va del sureste de Estados Unidos hasta América Central (Vázquez-García, 1994) y de un total de siete especies nativas registradas para México, seis pertenecen a dicha sección.

Magnolia guerrerensis J.Jiménez Ram., K.Vega et R.Cruz sp. nov. Figura 1.

Arbor 6-20 (-25) $\mathrm{m}$ alta. Stipulae fere glabrae, paucis trichomatibus. Folia elliptica, semper glabra, (7.8-) 8-13.3 (-14) cm longa, 4.2-5.4 cm lata. Pedunculus glaber, 2.12.8 (-3.3) cm longus. Bracteae 2-3.2 longa e, $2.8 \mathrm{~cm}$ latae. Pedicellus glaber, (1.7-) 2.7-3.3 (-3.5) cm longus. Sepala 3, oblonga, 2.5-3.5 (-4) cm longa, $1-1.5 \mathrm{~cm}$ lata. Petala 6, oblongo-obovata, apice apiculata vel acuta, ra re rotundata, (3.3-) 3.5-4.5 longa, 1.2-1.5 lata. Stamina (25-) 42-50, acuminata apice. Receptaculum coccineum insertione and roecii. Gynoecia cum 12-15 pistillis.

TIPO: México, Guerrero. Mpio. Leonardo Bravo, 13 km de la desviación a Yextla, $17^{\circ} 33^{\prime} 39.7^{\prime}$ 'N y 99 52' 50'O, alt. 2,290 m, bosque mesófilo de montaña, 15 junio 2006. J. Jiménez-Ramírez y K. Vega-Flores 1560 (Holotipo: FCME; Isotipos: por distribuirse).

Árboles 6-20 (-25) m de alto, ramificación a partir de una altura de 2-4 m; ramas verdosas, con lenticelas prominentes amarillas, ramillas glabras. Hojas 1.1-1.8 (-2) cm, elípticas, pecíolo semirrollizo, acanalado, glabro. Lámina (7.8-) 8-13.3 (-14) × 4.2-5.4 cm, elíptica, haz y envés gla- bros, con venación reticulada evidente, ápice agudo a ligeramente acuminado, base obtusa a ligeramente cuneada. Estípulas $1.2-3 \times 0.4 \mathrm{~cm}$, verdes, glabras y con tricomas escasos en el ápice. Flores terminales, diámetro 4-7 cm; pedúnculos 2.1-2.8 (-3.3) cm de largo, glabros, con lenticelas. Brácteas 2, $3.2 \times 2.8 \mathrm{~cm}$, glab ras; pedicelo (1.7-) 2.7-3.2 (-3.6) mm de largo, glabro, verde claro. Sépalos 3, 2.5-3.5 $(-4) \times 1-1.5 \mathrm{~cm}$, oblongos, en posición horizontal en la antesis, haz blanco, envés verdoso a pardo. Pétalos externos 3, (3.3-) $4.5 \times$ (1.5-) $2 \mathrm{~cm}$, blancos, oblongo-obovados. Pétalos internos $3,3.5 \times 1.2 \mathrm{~cm}$, blancos, oblongo-obovados. Estambres (25-) 42-50, 1-1.1 ×0.15 cm, con ápice acuminado, el receptáculo color rojo cereza y consistencia carnosa. Gineceo 1.2-1.5 (-2) × 0.5-0.8 cm, oblongo, verde claro, glabro. Carpelos 10-16, 0.8-1 cm de largo, estigmas papilados, curvos, blancos. Polifolículo $4.1 \times 2.2 \mathrm{~cm}$, oblongo, verdoso cuando joven, glabro, folículos 12-16. Folículo $2.4 \times 0.8 \mathrm{~cm}$. Semillas no vistas.

Distribución y ecología. Esta especie presenta botones florales en marzo, florece en mayo, julio y agosto y fructifica en marzo. Se distribuye en bosque mesófilo de montaña, en altitudes de (1950-) 2,200-2,400 m. Comúnmente se asocia a Persea, Quercus, Pinus y Clethra, en suelos profundos con hojarasca abundante.

La especie nueva es parecida a Magnolia schiedeana S chltdl. pero difiere (ver la clave que se presenta al final de este párra fo) de ésta por tener estípulas más pequeñas y glabras, brácteas más largas y estre chas, pedúnculo más largo, pedicelo bien desamollado, sépalos oblongos, con el envés ve rde a pardo y ápice obtuso a agudo, pétalos obl ongo-obovados en los que la porción más ancha ocupa casi la mitad superior de su limbo, anteras con ápice acuminado, gineceo con 10-16 pistilos y fruto con 10-16 folículos. Para hacer la comparación se utilizaron ejemplares de herbario y se observaron ejemplares vivos de $M$. schiedeana $\mathrm{S}$ chltdl. en el Jardín Botánico Javier Clav i j e rodel Instituto de Ecología A. C. e individuos silve stres de las cercanías de Xalapa, Veracruz, dado que el lectotipo de Schiede $y$ Deppe 296 (P) fue recolectado entre esta ciudad y Acajete (antes San Salvador), Veracruz, México (Vázquez-García, 1994).

Clave para diferenciar a $M$. guerrerensis sp. nov. de $M$. schiedeana Schltdl.:

1. Estípulas $4.5-5 \mathrm{~cm}$ de largo, generalmente pubescentes, muy rara vez glabras; brácteas $3 \times 3.1 \mathrm{~cm}$; pedúnculo 1 $1.7 \mathrm{~cm}$ de largo; pedicelo reducido e indistinguible; sépalos obovados, envés verde claro, ápice redondeado; pétalos obovados, la porción más ancha ocupa aproximadamente 4/5 de la porción superior de su longitud, ápice redondeado o emarginado; ápice de la antera agudo, la porción del receptáculo donde se inserta el androceo es 


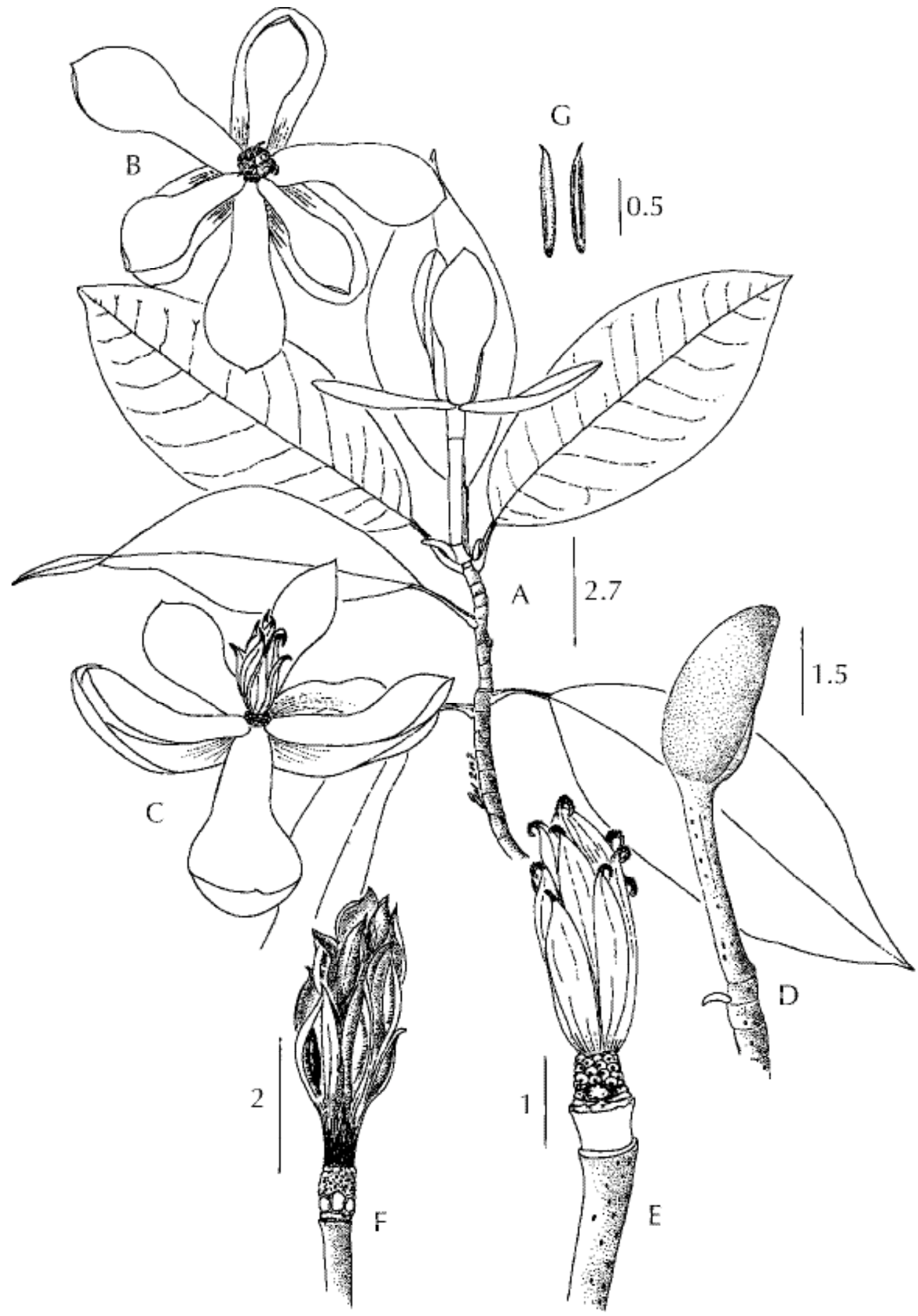

Figura 1. Magnolia guerrerensis J.Jiménez Ram., K.Vega et R.Cruz sp. nov. (a) Rama con flor parcialmente en antesis. (b) Flor en antesis, vista apical. (c) Flor en antesis, vista lateral. (d) Botón floral. (e) Gineceo parcialmente maduro. (f) Polifolículo. (g) Estambres, vista dorsal y ventral. [a-e. J. Jiménez y K. Vega 1561 (FCME); f. L. Lorenzo 430 (FCME); g. J. Jiménez y K. Vega 1561 (FCME)]. Escalas en cm. Ilustración Ramiro Cruz Durán. 
blanca; gineceo con 21-35 pistilos; fruto con 21-35 folículos. M. schiedeana

1. Estípulas 1.2-3 cm de largo, glabras con algunos tricomas en el ápice; brácteas de $3.2 \times 2.8 \mathrm{~cm}$; pedúnculo de 2.8-3.3 cm de longitud; pedicelo (1.7-) 2.7-3.2 (-3.6) $\mathrm{mm}$ de largo; sépalos oblongos, envés verdoso a pardo, ápice obtuso a agudo, frecuentemente con un diminuto ápiculo; pétalos oblongo-obovados, la porción más ancha ocupa poco más de la mitad superior de su longitud, ápice apiculado o agudo, rara vez redondeado; antera con el ápice acuminado; gineceo con 10-16 pistilos; fruto con 12-16 folículos. M. guerrerensis sp. nov.

Ejemplares adicionales examinados. México, Guerrero. Mpio. General Heliodoro Castillo, Escalerilla, km 139, carr. Atoyac a Xochipala, alt. 2,400 m, 31 enero 1983. L. Lorenzo 430 (FCME). Mpio. Leonardo Bravo, $13 \mathrm{~km}$ de la desviación a Yextla, alt. 2,290 m, 3 agosto 2006. K. Vega 852, 853 (FCME). 15 junio 2006, J. Jiménez y K. Vega 1561 (FCME). Aprox. $3 \mathrm{~km}$ al NE de Cruz de Ocote, alt. 2,210 m, 24 marzo 1985. F. Lorea 3490 (FCME). Mpio. Quechultenango, Volcán Negro, al NO de Mezcaltepec, alt. 2,200 m, 29 mayo 1972. Halbinger s. n. (MEXU), alt.
1,950 m, 11 junio 1999. G. Piña y Urlett s. n. (IBUG), alt. 2,331-2,347 m, 18 marzo 2007. J. Jiménez y K. Vega 1630, 1631 (FCME, IBUG).

\section{Agradecimientos}

A. Richard B. Figlar y Hans P. Nooteboom por sus valiosas observaciones y sugerencias al manuscrito. A Martha J. Martínez Gordillo por elaborar la diagnosis latina, a Susana Valencia Ávalos, quien aportó acertadas sugerencias al manuscrito, a Jorge A. Meave por todas las atenciones para la publicación de este artículo y Miguel Equihua, director del Instituto de Ecología, A.C., por las facilidades otorgadas en el Jardín Botánico Javier Clavijero, Xalapa, Veracruz.

\section{Literatura citada}

Figlar R.D. y Nooteboom H.P. 2004. Notes on Magnoliaceae IV. Blumea 49:87-100.

Vázquez-García J.A. 1994. Magnolia (Magnoliaceae) in Mexico and Central America: A sinopsis. Brittonia 46:1-23.

Vázquez-Garáa J.A., Carvajal S. y Hernández L.L. 2002. Magnolia pugana (Magnoliaceae): una nueva combinación en el complejo M. pacifica. Novon 12:137-141.

Recibido: 7 de marzo de 2007

Versión corregida: 7 de mayo de 2007

Aceptado: 8 de mayo de 2007 